Revista Mídia e Cotidiano ISSN: 2178-602X

Resenha

Volume 15, Número 3, set./dez de 2021

\title{
Psicopolítica: o neoliberalismo e as novas técnicas de poder
}

\section{Psychopolitics: neoliberalism and new power technique}

\section{Psicopolítica: neoliberalismo y nuevas técnicas de poder}

\author{
Jadson MAIA ${ }^{1}$ \\ Patricia SILVA ${ }^{2}$ \\ Cristina ALMEIDA ${ }^{3}$
}

HAN, Byung-Chul. Psicopolítica: o neoliberalismo e as novas técnicas de poder. Tradução de Maurício Liesen. Belo Horizonte: Editora Ayiné, 2018b.

\section{Introdução}

"Proteja-me do que quero" é o aviso sutil inerente ao capitalismo contemporâneo, explica Byung-Chul Han (2018b, p. 28) em Psicopolitica: o neoliberalismo e as novas técnicas de poder. Embora seja característico desse filósofo sul-coreano ser breve na exposição de seus pensamentos, não é seu perfil oferecer uma leitura tranquila - ele acaba por conceber doses homeopáticas de desconforto. Ensaísta radicado na Alemanha, Han leciona na Universidade de Berlim. Sua elaboração teórica é voltada para a relação entre o neoliberalismo e a vida psicológica dos indivíduos, como

1 Doutor em Ciências Sociais e Mestre em Estudos da Mídia, ambos pela Universidade Federal do Rio Grande do Norte (UFRN). Tem especialização em Propaganda e Marketing na Gestão de Marcas pela UFRN e é graduado em Comunicação Social com Habilitação em Publicidade \& Propaganda pela Universidade Potiguar (UnP). E-mail: jadsonmaia@ufrn.edu.br. ORCID: https://orcid.org/0000-00030148-3975.

2 Graduada (2015) e mestre (2019) em Ciências Sociais pela Universidade Federal do Rio Grande do Norte. Atualmente é doutoranda e bolsista (CAPES) pelo Programa de Pós-Graduação em Ciências Sociais da UFRN. Pesquisadora do Grupo Marginália (Grupo de Estudos Transdisciplinares em Comunicação e Cultura). E-mail: patriciarilrn@ hotmail.com. ORCID: 0000-0002-1345-5536.

3 Mestre em Ciências Sociais pela Universidade Federal do Rio Grande do Norte, bacharel em Comunicação Social, habilitações Radialismo e Jornalismo, pela mesma instituição. E-mail: cristinaalmeida@ufrn.edu.br. ORCID: 0000-0001-7787-6471. 
podemos observar em obras como Sociedade do cansaço (HAN, 2015), No enxame: perspectivas do digital (HAN, 2018a) e $O$ que é poder? (HAN, 2019). No livro objeto desta resenha, o autor dirige proposições cirúrgicas para pensar como "a liberdade e a comunicação ilimitada se transformaram em monitoramento e controle total" (HAN, 2018b, p. 19).

O argumento fundamental é a autoexploração como aspecto paradoxal da nossa condição no regime neoliberal, pois, conforme o autor desenvolve: "é a exploração da liberdade que produz o maior lucro" (HAN, 2018b, p. 12). O sentimento de liberdade atual consiste no esboço de projetos individuais e livres que se reinventam incessantemente. Tal sensação se estabelece no ínterim de uma forma de vida à outra. Assim, “a liberdade terá sido episódica” (HAN, 2018b, p. 9), porque, inevitavelmente, uma nova forma de sujeição sobrevém. Não se trata exatamente de coerção no sentido disciplinar, mas, sim, de uma forma mais eficiente de subjetivação e sujeição, uma vez que o "eu", como projeto, se submete às coações internas construídas pelo desempenho e pela otimização permanentes. "Vivemos em um momento particular, no qual a própria liberdade provoca coações" (HAN, 2018b, p. 9) e, embora acreditemos ser livres, exploramos voluntariamente a nós mesmos, assegura o pensador.

No contexto político e econômico presente, o sujeito é um empreendedor de si mesmo, inclinado a agir sempre individualmente e, dessa maneira, não é capaz de estabelecer relações livres de propósito, já que, segundo Han (2018b), entre sujeitos neoliberais não se cultiva amizade desinteressada. Nesse aspecto, o filósofo acena mais uma provocação: liberdade e amigo possuem a mesma raiz indo-europeia, isto é, a palavra liberdade remete, em sua origem, a estar entre amigos. Isso implica dizer que o isolamento exacerbado, característico do neoliberalismo, é contraditório com a essência relacional da liberdade. Han 2018b) traz Karl Marx para o diálogo, ao afirmar que a liberdade individual representa uma astúcia do capital. A produção é otimizada através da liberdade individual; o capital multiplica-se enquanto competimos e interiorizamos suas dinâmicas de acumulação. Em outras palavras, o capital explora a liberdade para se reproduzir e, desse modo, o indivíduo pode ser descrito, usando os termos cáusticos do autor, como “órgão genital do capital”. A tal liberdade individual, segue provocando Han (2018b), serve ao capital como subjetividade automatizada para a produção. 
O autor argumenta que, diferente do pensamento marxiano, a contradição entre as forças produtivas e as relações de produção é insuperável. Assim, destaca que o capitalismo sempre se reinventa e afirma ainda que não foi o comunismo que eliminou a exploração alheia da classe trabalhadora, foi o neoliberalismo. O que está em questão é efetuar uma crítica que tenta dissolver um paradigma da esquerda clássica. O servo e o senhor são figuras incorporadas na mesma pessoa; a luta de classes passa a ser uma luta interior consigo mesmo; é equivocado acreditar que o sujeito atual faça parte de uma multitude (termo usado pelo autor com base na obra de Antonio Negri) cooperante e capaz de finalizar o império parasitário, instaurando uma ordem social comunista. A partir dessa autoexploração e do isolamento do sujeito do desempenho, não é possível se formar um "nós" político ou um agir comum. Não há meios para questionar o sistema, pois somos os responsáveis por qualquer fracasso - a vergonha de si avança ao passo que qualquer iniciativa de resistência é sufocada. Não à toa, nesse regime de autoexploração não existem revolucionários, apenas depressivos que se julgam insuficientes pelas suas autocobranças.

Ademais, construímos e participamos voluntariamente do que Han (2018b) chamou de pan-óptico digital, distinto do pan-óptico desenvolvido pelo filósofo inglês Jeremy Bentham, em 1785 - um tipo de penitenciária ideal, na qual muitos são vigiados por poucos. Porém, nesta última, há diversos pontos cegos e se destina, sobretudo, a disciplinar os corpos. No pan-óptico digital, que estrutura as redes sociais digitais, por exemplo, e atualiza essa lógica, o indivíduo se expõe voluntariamente, sem a necessidade de coação externa, entregando seus dados. Han (2018b) considera que a sociedade de controle faz, portanto, uso da liberdade e da transparência como seus dispositivos principais.

As mídias sociais são os exemplos de pan-ópticos atuais, com arquitetura imaterial e acesso privilegiado ao psíquico e à subjetividade. Se o modelo benthamiano opera pelo confinamento e pela repressão externa, a sofisticação da vigilância contemporânea converte a negatividade da alteridade em positividade ${ }^{4}$. O pan-óptico

\footnotetext{
4 Byung-Chul Han usa os termos positividade e negatividade como dimensões conceituais da condição humana. A positividade compreende o poder fazer e o desempenho que alimenta a vida moderna, fluida e sem interrupções, enquanto a negatividade corresponde à capacidade de hesitar ou de um parar interior que, embora seja fundamental para nossa vida psíquica, é suprimida no neoliberalismo.
} 
digital estimula a comunicação e o consumo irrestritamente, a conexão e a comunicação são totais. Cria-se, assim, um efeito nivelador, sob o qual nos vigiamos mutuamente antes mesmo de qualquer vigilância secreta: "é uma vigilância sem vigilância” (HAN, 2018b, p. 21). Han (2018b) afirma que a comunicação em rede é uma positividade que carece de interioridade, facilitando sua hipercirculação com autonomia em relação ao contexto, em que o segredo e a alteridade são como barreiras à positividade do fluxo. O reflexo disso na política é a formação de uma democracia de espectadores a serem escandalizados eles participam reclamando como consumidores e não como cidadãos engajados em um agir político comum. Transformados em mero público e sujeitos atomizados, apenas reclamam passivamente, como faz um consumidor quando não está satisfeito com um produto ou serviço.

A era da psicopolítica digital e dos big data compreende um conhecimento de dominação capaz de intervir na psique e de influenciá-la em um nível pré-reflexivo; suas inferências possibilitam prognósticos do comportamento humano, de modo que, para Han (2018b), representa o fim do livre-arbítrio. O próprio uso do smartphone corresponde a um aparato de subjetivação comparável a um rosário, pois “ambos envolvem autocontrole e exame de si. Curtir é o amém do digital" (HAN, 2018b, p. 24), além disso, "o sujeito submisso nunca é consciente da sua submissão" (HAN, 2018b, p. 26). Podemos até achar um pensamento drástico, mas não é fácil apresentar argumentos contra o fato de que "a psicopolítica digital transforma a negatividade da decisão livre na positividade de um estado de coisas" (HAN, 2018b, p. 23).

O poder não se opõe a liberdade, esclarece Han (2018b). Pelo contrário, a necessidade de violência em si já é uma demonstração de pouco poder e sua expressão máxima está onde este não é em evidência — o poder "se dá sem ter que apontar ruidosamente para si” (HAN, 2018b, p. 25). Sua eficiência consiste em não agir pela proibição, mas pela emoção e pela satisfação; não se almeja indivíduos obedientes, mas dependentes; o poder inteligente produz emoções positivas e as explora, "se plasma à psique, em vez de discipliná-la e submetê-la a coações e proibições" (HAN, 2018b, p. 27). A psicopolítica digital nos convida a compartilhar, a participar, a dar opinião, expressar nossas necessidades, desejos e preferências. Dito isso, já podemos acender o 
alerta de que é sim possível: "o poder inteligente lê e avalia nossos pensamentos consciente e inconsciente" (HAN, 2018b, p. 28).

Nesse sistema baseado na auto-organização e na otimização pessoal, Deleuze (1992, apud Han 2018b) sublinha que vivenciamos uma crise generalizada institucional e de seus ambientes de reclusão, tais como família, escola, prisão, hospital, fábrica etc. Isso sugere que há uma profunda transformação em curso do que Michel Foucault (1977) denominou de sociedade disciplinar, segundo a qual os indivíduos são organizados no espaço e no tempo. A técnica de governança da sociedade disciplinar é a biopolítica que, segundo a analogia animalesca feita pelo autor, comporta-se como uma toupeira, e usase a estatística demográfica para administrar a população como massa de produção, controlando, por exemplo, a taxa de natalidade e de mortalidade. Porém, tal rigidez é incompatível com a sociedade do controle - quer dizer, com o neoliberalismo e seu modo de produção imaterial. Nessa última, é a psicopolítica, comparada a uma serpente pelo autor, que assume a condição de técnica de governança predominante e utiliza-se dos big data como instrumento de controle da psique. Diferentemente da estatística utilizada na biopolítica, os big data ou dataísmo fornecem um psicograma individual e coletivo, e, talvez, um psicograma do inconsciente, especula Han (2018b).

Portanto, "o disciplinamento corporal dá lugar à otimização mental” (HAN, 2018b, p. 40), isto é, a psicopolítica garante que o próprio indivíduo reproduza a submissão dentro de si e compreenda isso como liberdade. É dessa forma que coincidem a otimização de si e a submissão, a liberdade e a exploração, e, funda-se a era do esgotamento, afinal, "hoje se explora a psique" (HAN, 2018b, p. 46). A sociedade de controle oferece uma espécie de cura, experiências motivacionais e treinamentos de inteligência emocional, um bem-estar transitório em prol da eficiência e do desempenho, no entanto, mais uma vez, Byung-Chul Han (2018b) joga suas pílulas de perturbação ao afirmar que "a otimização pessoal permanente, que coincide em sua totalidade com a otimização do sistema, é destrutiva. Ela conduz ao colapso mental” (HAN, 2018b, p. 46). Essa indústria da consciência destrói a alma humana e a "cura se torna assassinato" (HAN, 2018b, p. 48).

Mais uma vez, o filósofo e ensaísta justifica a precisão do seu ponto de vista para analisar a contemporaneidade marcada pelas mutações do capitalismo. Em diálogo com 
a obra Doutrina de choque, de Naomi Klein (2008), Han (2018b) compreende que o olhar da autora, assim como o de Foucault, permanece ainda preso nas técnicas de poder da sociedade disciplinar. A terapia de choque é genuinamente disciplinar, seja os experimentos de eletrochoque coordenados pelo psiquiatra canadense Ewen Cameron, na crença de banir completamente o mal dos pacientes, ou do teólogo neoliberal Milton Friedman, que enxergava o momento de pós-catástrofe ${ }^{5}$ como oportunidade para reprogramar toda a sociedade segundo novos desígnios econômicos. A ausência de sutileza, sofisticação e positividade fazem dela uma técnica explícita de coação externa.

O foco desse poder não é mais administrar o passado, mas, sim, o controle psicopolítico do futuro. É fundamental ressaltar ainda que a transparência e a informação não são sinônimos de verdade para Han (2018b); pelo contrário, elas substituem a verdade. Dessa maneira, "a comunicação coincide inteiramente com o controle, cada um é o pan-óptico de si mesmo" (HAN, 2018b, p. 58). Isso se expressa no uso ilimitado da liberdade e da multiplicação de palavras, "nesse pan-óptico digital não se é torturado, se é tuitado ou postado" (HAN, 2018b, p. 56), em contraste com a sociedade totalitária ilustrada pelo clássico da literatura universal de George Orwell, intitulado 1984, no qual os delitos do pensamento são reprimidos com a redução das palavras como, por exemplo, o próprio termo liberdade, que deixa de existir.

Fala-se muito no excesso de sentimentos e emoções na sociedade do controle, entretanto, Han (2018b) chama a atenção para a confusão conceitual entre emoção, afeto e sentimento. Diferentemente do afeto e da emoção, o sentimento apresenta uma profundidade narrativa; é constitutivo, haja vista que podemos dizer "tenho o sentimento de...”. O mesmo não pode ser dito sobre o afeto e a emoção, pois ambos não são constitutivos, são performativos e remetem a ações intencionais e finalistas. Nem o afeto nem a emoção são narráveis, não abrem nenhum espaço, apenas procuram uma via linear para serem descarregados. Assim, muito bem adaptados à temporalidade do médium digital, as "shitstorms são correntes de afetos e são características da comunicação digital”

5 Catástrofe aqui pode ser um desastre ambiental, uma severa crise econômica ou política, seu sentido é amplo. Porém, o que interessa é que a desestabilização social que a catástrofe realiza é pensada por Friedman como um momento oportuno para empregar os princípios do regime neoliberal. 
(HAN, 2018b, p. 60). Em suma, no capitalismo da emoção, estamos imersos em um mar de afetos e o que vivemos hoje é uma crise dos sentimentos.

A essa altura da leitura, já é notório que é um equívoco subestimar o presente livro pelo seu tamanho. Porém, ainda há mais provocações ácidas, o autor acrescenta que o capitalismo da emoção também se apropria das dinâmicas do jogo, ao passo que isso mobiliza e dramatiza o trabalho, criando mais motivação. É por meio da sensação de realização e do sistema de recompensas que o jogo gera mais desempenho e rendimento, pois o jogador se envolve muito mais do que o trabalhador meramente funcional que age no nível racional. Assim, trata-se do que o autor chama de gamificação do trabalho, processo no qual nos submetemos às relações de dominação enquanto jogamos. Essa lógica se evidencia na comunicação social, através de likes, de amigos ou de seguidores. Desse modo, a gamificação da comunicação implica na sua comercialização. Todavia, a liberdade só pode ser esperada no outro do trabalho, ela só pode existir em uma força totalmente diferente da força de trabalho, totalmente improdutiva ou do ócio: "nosso futuro dependerá de sermos capazes de fazer uso do inutilizável para além da produção" (HAN, 2018b, p. 72).

O homem é uma criatura do luxo, analisa Han (2018b), mas no sentido original do termo, a saber, uma forma de vida que está livre da necessidade, e isso faz do luxo uma condição íntima da liberdade. Entretanto, o luxo na contemporaneidade é monopolizado pelo consumo excessivo e recai na falta de liberdade. Bem como o jogo, o luxo só pode coadunar com a liberdade se não estiver relacionado com o trabalho e com o consumo. "A verdadeira felicidade se deve ao extravagante, ao exuberante, ao abundante, ao esvaziado de sentido, ao excedente, ao supérfluo, ou seja, àquilo que desvia da necessidade, do trabalho, do desempenho, da finalidade" (HAN, 2018b, p. 73), logo, a gamificação como meio de produção arruína o caráter emancipatório do jogo. Este é capaz de nos livrar da teologia e da teleologia do capital por meio da profanação, que significa devolver ao homem o livre uso daquilo que pertencia aos deuses, que era sagrado e espiado. O que aconteceria se profanássemos o dinheiro, se o tornássemos um brinquedo profano?

De acordo com Han (2018b), profanação é uma prática da liberdade; ela nos liberta da transcendência e das formas de subjetivação e abre um espaço de jogo da 
imanência. Trata-se de um espaço-acontecimento, no qual suprimimos qualquer modo de subjetivação e de trabalho. No entanto, o dataísmo, a crença na mensurabilidade e na sua eficiência vigilante, pode espionar até a psique. O preço disso é que "o si mesmo é desmanchado em dados até que se torne insignificante" (HAN, 2018b, p. 84), pois, mesmo que sejam abundantes, os dados não são capazes de produzir autoconhecimento. "O dataísmo, ao contrário, esvazia o automonitoramento (self-tracking) de qualquer ética e verdade e o transforma em mera técnica de autocontrole" (HAN, 2018b, p. 85). Transforma-se, portanto, em uma prisão de memória total, já que nossos hábitos digitais fornecem uma representação muito exata de nossa alma. Os big data são, em última análise, um grande negócio — nossos rastros digitais são comercializados à medida em que somos tratados como pacotes de dados.

Para finalizar, Deleuze (2008, apud Han, 2018b), faz um elogio ao idiota. Este seria aquele que se nega a se conformar, tem um corpo hipersensível e está aberto à alteridade, ao outro. Então, o filósofo seria o idiota por excelência. O poder encontra na figura do idiota uma negatividade que deve ser combatida, pois é um obstáculo às técnicas de vigilância e controle que anseiam ser totais. O idiota, assim, encarna a pura imanência da vida, não sendo um mero sujeito, mas alguém que se deixa perpassar pela potência e talvez escape de se subjetivar pela psicopolítica digital. Com efeito, é conveniente retomar ao início: "proteja-me do que quero", afinal o paradigma emergente de poder embaralha as cartas do que é liberdade e opressão.

\section{Referências}

HAN, Byung-Chul. No enxame: perspectivas do digital. Tradução de Lucas Machado. Petrópolis, RJ: Vozes, 2018.

HAN, Byung-Chul. O que é poder? Tradução de Gabriel Salvi Philipson. Petrópolis, RJ: Vozes, 2019.

HAN, Byung-Chul. Psicopolítica: o neoliberalismo e as novas técnicas de poder. Tradução de Maurício Liesen. Belo Horizonte: Editora Ayiné, 2018b.

HAN, Byung-Chul. Sociedade do cansaço. Tradução de Enio Paulo Giachini. Petrópolis, RJ: Vozes, 2015.

FOUCAULT, Michel. Vigiar e punir. Petrópolis: Vozes, 1977. 